\title{
The Degree of Diabetic Wounds Affects Kidney Function Damage
}

\author{
Emyk Windartik ${ }^{1}$, Ima Rahmawati ${ }^{1}$, Ita Ainun Jariyah ${ }^{1}$, Raras Merbawani ${ }^{1}$, Indah \\ Lestari $^{2}$, Ifa Ro'ifah ${ }^{1}$, Arief Andriyanto ${ }^{3}$ \\ ${ }^{I}$ Department of Basic Nursing, STIKes Bina Sehat PPNI Mojokerto, East Java, Indonesia \\ ${ }^{2}$ Department of Maternity Nursing, STIKes Bina Sehat PPNI Mojokerto, East Java, Indonesia \\ ${ }^{3}$ Department of Community Nursing, STIKes Bina Sehat PPNI Mojokerto, East Java, Indonesia \\ Corresponding Author:Ima Rahmawati (ima_rahmawati91@yahoo.co.id)
}

\begin{abstract}
Background: The peripheral neuropathy is the cause of hospitalization for patients with diabetes mellitus (DM) and damages kidney function due to the circulatory system with high sugar levels. High sugar levels in DM patients with diabetic wounds can trigger glomerular damage resulting in the decrease of kidney function.

Purpose: This study aims to analyze the relationship between the degree of diabetic wounds and kidney functions in patients with DM.

Methods: A cross-sectional study was conducted on 723 DM patients who experienced diabetic wounds in a hospital in Mojokerto, East Java, Indonesia. A purposive sampling technique was used to recruit the samples. The data of this study were medical records of diabetic patients. A simple linear regression test was employed to analyze the data.

Results: The result showed that the degree of the diabetic wound was significantly related to kidney function damage $(p=0.000)$. The relationship between the degree of diabetic wounds and the decline in kidney function was shown by an R-squared value of 0.768 , meaning that the degree of diabetic wound affected the decline of kidney function by $76.8 \%$, while the $23.2 \%$ was affected by other factors.

Conclusion: The degree of diabetic injury affects the decline of kidney function in DM patients by $76.8 \%$. Nurses should do health promotion about controlling blood sugar levels in DM patients with the prevention of four pillars of diabetes, including education, nutrition, physical activity, and stress.
\end{abstract}

Keywords: Diabetes mellitus; diabetic wounds; kidney function

How to Cite: Windartik, E., Rahmawati, I., Jariyah, I.A., Merbawani, R., Lestari, I., Ro'ifah, I., Andriyanto, A. (2019). The degree of diabetic wounds affects kidney function damage. Nurse Media Journal of Nursing, 9(2), 159-166. doi: 10.14710/nmjn.v9i2.24210

Permalink/DOI: https://doi.org/10.14710/nmjn.v9i2.24210

\section{BACKGROUND}

Diabetes mellitus (DM) is a chronic metabolic disorder related to increased levels of glucose in the blood (Nejhaddadgar, Darabi, Rohban, Solhi, \& Kheire, 2018). 
According to the World Health Organization [WHO] (2016), the prevalence of diabetes among adults over 18 years reached $8.5 \%$. Elevated glucose levels in the blood cause microvascular development (blindness, nephropathy, and neuropathy) and macrovascular degenerative complications (cardiovascular and stroke) due to uncontrolled blood glucose levels (Laddha \& Kulkarni, 2019). According to Abu AlHalaweh et al. (2017), most of the complications that occurred in 794 diabetic patients were; 307 patients $(38.7 \%$ ) having a history of microvascular disease, 239 patients (83\%) having retinopathy, 83 patients $(28.5 \%)$ having peripheral neuropathy, $18.9 \%$ having advanced nephropathy, and $12.2 \%$ experiencing myocardial infarction (MI).

Peripheral neuropathy is the cause of hospital care for the DM patients who experience the damage of kidney function because of high sugar levels, although this problem can be prevented (Chao-Hung, Kun-Der, Ke, \& Liang, 2019). Patients with this disease have a higher risk of morbidity, mortality, and hypoglycemia than those who do not experience it (Chowdhury, Khan, Lasker, \& Chowdhury, 2019). The prevalences of microalbuminuria, proteinuria, and a decrease in glomerular filtration rate are $36 \%, 8 \%$, and $22 \%$, respectively. The presence of albuminuria is a predictor of chronic kidney disease. Diabetic kidney disease, known as diabetic nephropathy, refers to kidney disease caused by diabetes (Carretero Gómez \& Arévalo Lorido, 2018).

Type-2 DM is the main cause of chronic kidney disease (CKD). CKD patients with type-2 DM have more significant morbidity and mortality and a risk of hypoglycemia than people who have normal kidney function. The impact of type-2 DM on the healthy population is based on its high prevalence and socioeconomic costs, because microvascular and macrovascular complications are the significant causes of death (Avogaro \& Fadini, 2019). Based on the results of previous studies, 30-40\% of people with type-1 DM and 20-30\% of people with type-2 DM will suffer from diabetic nephropathy, which will eventually lead to kidney failure (Rivandi \& Yonata, 2015). The occurrence of terminal kidney failure can affect the patients' quality of life (Sari \& Hisyam, 2014). This complication arises from the presence of foot lesions and the possibility that diabetic patients will face amputation. Diabetic nephropathy becomes the most common cause of morbidity and the main determinant of death in diabetic patients (Laddha \& Kulkarni, 2019).

Abu Al-Halaweh et al. (2017) in their study showed poor glycemic control in Palestine, while blood pressure and lipids were less poorly controlled. Other studies have also obtained that the risk of CKD and its severity in diabetic patients increase with age (Hughes-Carter, Liu, \& Hoebeke, 2018). In the US, the incidence of end-stage renal failure in 2014 for those aged 22 to 44 years old was 128.8 per million. The incidence jumps to 1,265 per million for those aged 65 to 74 years and to 1,556 per million for those older than 75 years. National and international organizations assert that further research is needed concerning CKD in the elderly to guide screening and treatment better. The Kidney Disease: Improving Global Outcomes (KDIGO) CKD Work Group recommends the following tests yearly for those with diabetes: (1) urine microalbuminto-creatinine ratio, (2) estimated glomerular filtration rate (eGFR), and (3) serum creatinine. However, national data show that only $33.3 \%$ of medicare beneficiaries with diabetes had annual urine microalbumin screening, and $33.8 \%$ of people aged 65 and 
elder with CKD obtained recommended serum creatinine, lipids, and microalbuminuria together with a medical evaluation (United States Renal Data System, 2018). Previous studies showed that peripheral neuropathy resulting in diabetic wounds was the most problem experienced by diabetic patients with kidney damage. However, little evidence was known about whether the diabetic wound affects kidney function in diabetic patients. Therefore, research to study the relationship between diabetes wounds and kidney function damage is needed.

\section{PURPOSE}

The purpose of this study was to analyse the relationship between the degree of diabetic wounds and kidney function in patients with DM.

\section{METHODS}

\section{Research design}

The research design was a correlational analysis using a cross-sectional approach.

\section{Samples and setting}

The population in this study was all diabetic patients who suffered from diabetic wounds in a hospital in Mojokerto District in 2018. The research used a simple random sampling method to obtain the total samples of 723 patients.

\section{Research instrument and data collection}

The independent variable used in this study was the degree of diabetic injury with an ordinal data scale, and the dependent variable was kidney function with an interval data scale. Data were collected using secondary data from the medical records. These medical record data were medical diagnoses for the degree of diabetic wounds and laboratory results of serum creatinine for kidney function. The classification of kidney function damage in this study according to LFG values are; Degrees 1 with values of more than 90; Degrees 2 with values of 60-90; Degrees 3 with values of 28-59; Degrees 4 with values of 15-29; and Degrees 5 with values of less than 15.

\section{Data analysis}

The data analysis used a simple linear regression test to determine the relationship between the degree of diabetic wounds and kidney function. Meanwhile, the statistical test for all analyses had a significance level of $95 \%$ (alpha 0.05 ).

\section{Ethical consideration}

This study received ethical approval from the ethics committee at Sumber Gelagah hospital in Mojokerto, Indonesia. Furthermore, the ethical principles were also observed throughout this study.

\section{RESULTS}

The characteristics of respondents in this study include gender and age. Table 1 shows that the majority of the respondents were women (59.8\%) with 3rd degree of diabetic wounds $(54.9 \%)$. The mean age and kidney functions were $56.5 \pm 9.53$ years and $43.5 \pm 18.25$, respectively. 
Table 1. Characteristics of respondents $(n=723)$

\begin{tabular}{|c|c|c|}
\hline Characteristics of respondents & $f$ & $\%$ \\
\hline Age & \multirow{2}{*}{\multicolumn{2}{|c|}{$56.5 \pm 9.532$}} \\
\hline$(\mathrm{Mean} \pm \mathrm{SD})$ & & \\
\hline GFR & & \\
\hline$($ Mean \pm SD) & \multicolumn{2}{|c|}{$43.5 \pm 18.25$} \\
\hline Gender & & \\
\hline Man & 291 & 40.2 \\
\hline Woman & 432 & 59.8 \\
\hline \multicolumn{3}{|l|}{ Degree of wound } \\
\hline Degree 1 & 0 & 0 \\
\hline Degree 2 & 149 & 20.6 \\
\hline Degree 3 & 397 & 54.9 \\
\hline Degree 4 & 177 & 24.5 \\
\hline
\end{tabular}

The model test obtained a $p$-value of 0.000 , meaning that $\mathrm{H} 0$ was rejected. This means that there was a relationship between the degree of diabetic injury and kidney function. In other words, the model can explain overall empirical data (Table 2).

Table 2. The model test of the degree of diabetic wounds to the decline in kidney function

\begin{tabular}{lrrrrl}
\hline Model & Sum of Squares & \multicolumn{1}{c}{ df } & Mean Square & F & \multicolumn{1}{c}{$p$} \\
\hline Regression & 184801.514 & 1 & 184801.514 & 2389.423 & 0.000 \\
Residual & 55763.219 & 721 & 77.341 & & \\
Total & 240564.733 & 722 & & & \\
\hline
\end{tabular}

The level of the relationship among variables was strong, with the value of r-0.876 in a negative direction. It means that the higher the degree of the injury, the lower the kidney function would be (Table 3).

Table 3. Relationships between diabetic wound degrees and decreased kidney function

\begin{tabular}{|c|c|c|c|c|c|}
\hline \multirow[t]{2}{*}{ Model } & \multicolumn{2}{|c|}{$\begin{array}{c}\text { Unstandardized } \\
\text { Coefficients }\end{array}$} & \multirow{2}{*}{$\begin{array}{c}\text { Standardized } \\
\text { Coefficients } \\
\text { Beta }\end{array}$} & \multirow[t]{2}{*}{ Counted t } & \multirow[t]{2}{*}{$p$} \\
\hline & $\mathrm{B}$ & Std. Error & & & \\
\hline \multirow{2}{*}{$\begin{array}{l}\text { (Constant) } \\
\text { diabetic } \\
\text { wounds }\end{array}$} & 115.965 & 1.518 & \multirow[b]{2}{*}{-0.876} & 76.383 & \multirow{2}{*}{$\begin{array}{l}0.000 \\
0.000\end{array}$} \\
\hline & -23849 & 0.488 & & -48.882 & \\
\hline
\end{tabular}

The estimated relationship was shown by the R-squared value of 0.768 , meaning that the degree of diabetic injury affected the decline of kidney function by $76.8 \%$, while $23.2 \%$ of the decrease in kidney function was affected by other variables (Table 4). 
Nurse Media Journal of Nursing, 9(2), 2019, 163

Table 4. The predictive value of the relationship

\begin{tabular}{cccccc}
\hline Model & $\mathrm{R}$ & $R$-Square & $\begin{array}{c}\text { Adjusted } R \\
\text { Square }\end{array}$ & $\begin{array}{c}\text { Std. Error of the } \\
\text { Estimate }\end{array}$ & $\begin{array}{c}\text { Durbin- } \\
\text { Watson }\end{array}$ \\
\hline 1 & 0.876 & 0.768 & 0.768 & 8.79440 & 1.804 \\
\hline
\end{tabular}

\section{DISCUSSION}

The results showed that patients with diabetic wounds had decreased kidney function in the degree of $3,4 \& 5$. Decreasing kidney function depends initially on the underlying disease. In DM, there is an obstruction of blood vessel flow resulting in diabetic nephropathy, where there is an increase in glomerular pressure resulting in mesangial expansion, glomerular hypertrophy. It will cause a reduction in the filtration area, which leads to glomerulosclerosis (Lee \& Chung, 2014). The high blood sugar levels in patients with diabetes mellitus who have diabetic wounds can lead to glomerular damage (Hughes-Carter et al., 2018). The condition can cause the kidneys to lose the ability to filter blood, so kidney failure and high blood pressure can also cause injury to the renal afferent arterioles. The worst condition is it can decrease infiltration, which causes diabetic nephropathy (Carretero Gómez \& Arévalo Lorido, 2018; Limkunakul et al., 2019). People with diabetes mellitus is potential to experience kidney damage, so they should take kidney function checks (Hsieh, Lee, Chen, Chang, \& Han, 2016).

The high blood sugar levels will make the kidney structure change, and it will disturb the functions (Ghandour et al., 2018). Besides, the results of another studiy found that a significant proportion of people with type-2 DM have weak macro and microvascular complications (MICRO) and metabolic control. Incidence of complications of diabetic nephropathy patients is $86.5 \%$, far higher than $58.6 \%$ of the control group (Chen, Wang, \& Huan, 2017). Glucose control in patients with diabetes is not less important than lipid and blood pressure control since hyperglycemia is the single most important risk factor for MICRO: once MICRO boosts the risk of CVD and HF, not only in patients with diabetes, but also in the general population, and much more if several MICRO of them co-exist. For these reasons, MICRO should represent a concern for cardiologists who should search and treat these conditions as it is exactly equally important for the diabetologist to search and recognize the importance of macrovascular complications (Avogaro \& Fadini, 2019).

Some investigators have preferred glomerular filtration rate (GFR) as the main parameter to detect glomerular injury in disturbances of glucose metabolism, considering that hyperfiltration is a high-risk condition for progressive kidney disease (Julia, de Almeida-Pititto, \& Ferreira, 2019). GFR elevation is dependent on increased plasma flow and glomerular pressure, even in the absence of systemic hypertension. Hyperglycemia-related hyperfiltration is attributed to afferent arteriolar vasodilation that leads to intraglomerular hypertension, increased transcapillary protein loss, and tubular sodium reabsorption. Abnormal GFR can be normalized by plasma glucose control, and microalbuminuria has been considered the hallmark of early diabetic microvascular disease in the kidney. More recently, the International Society of Nephrology stated that prognosis to chronic kidney disease should be based on both AER and GFR. Therefore, 
for the purpose of the present review, microalbuminuria and reduced GFR were taken as the major search terms (Lopes-Virella et al., 2019). Among the studies reviewed by Julia et al. (2019), the range of diabetic kidney disease (DKD) prevalence rates in prediabetes was wide, varying from a minimum of $4.5 \%$ to a maximum of $26.0 \%$. Taking into consideration two studies in which diagnosis was based on eGFR or six studies that used ACR, rate variation was similar. Presuming that microalbuminuria should precede the reduction of GFR in the natural history of diabetic kidney disease (DKD), it could be expected higher prevalence rates using AER rather than GFR. Several factors could be contributing to these findings.

Based on a simple linear regression test, the results also obtained that the degree of diabetic injury affected the decline of kidney function by $76.8 \%$, while $23.2 \%$ of the decrease in kidney function was affected by other variables. It is known that renal function is dependent on age, gender, genetic susceptibility, degree and duration of the hyperglycemic excursions, presence of comorbidities such as obesity, hypertension, smoking, and others. The main reason for such variability differences was age range, sample size, and genetic predisposition to renal diseases (Hsieh et al., 2016). Some of these factors also affect other problems in diabetic kidney disease (DKD).

The ways the disease is managed strongly influence the level of patient's productivity. Therefore, it is necessary to manage this disease comprehensively to make the patient's quality of life is optimal (Ghandour et al., 2018). The results of another study showed that the quality of life of patients with diabetes wounds is influenced by emotional factors, family, adherence, and friend support (Sari, Purnawan, Taufik, \& Sumeru, 2018). Family empowerment affected family support in patients with type-2 DM. Support provided by the family to patients with diabetes makes patients have selfmanagement to prevent complications (Luthfa \& Ardian, 2019).

The implications of the finding were essential in the care of diabetic patients with or without diabetic wounds. Patients with impaired kidney function have a higher risk of developing diabetic wounds. It requires intensive preventive care, especially if they also experience peripheral neuropathy. The correlation between a decrease in creatinine clearance and an increase in ulcer formation is linear. Thus, patients with the lowest creatinine clearance level are at the highest risk. However, after the lesion develops, individuals with impaired kidney function can expect their injuries to be no more severe than patients with normal kidney function. Therefore, it is crucial to identify the burden of complications of type-2 DM and understand the factors which contribute to the policy and decision-making processes related to prevention, management, and glycemic control.

\section{CONCLUSION}

The degree of diabetic wound affected the decline of kidney function. Diabetic wounds can trigger decreased kidney function because blood circulation in blood vessels decreases due to an increase in sugar levels. The continuous increase of blood sugar levels can cause damage to the glomerulus, which has a function as filtration in the nephrons in the kidneys. Therefore, people with diabetic wounds have a high risk of kidney function decline. As a recommendation, nurses should do health promotion 
about controlling blood sugar levels in DM patients with the prevention of four pillars of DM, including education, nutrition, physical activity, and stress to be able to take care of diabetic patients to prevent injuries and if diabetes sores can prevent on kidney function problems.

\section{ACKNOWLEDGMENT}

The researchers would like to thank STIKes Bina Sehat PPNI Mojokerto for the support to this study.

\section{CONFLICT OF INTEREST}

The authors declare no conflict of interest in this study.

\section{REFERENCES}

Abu Al-Halaweh, A., Davidovitch, N., Almdal, T. P., Cowan, A., Khatib, S., NasserEddin, L., \& Baradia, Z. (2017). Prevalence of type 2 diabetes mellitus complications among Palestinians with T2DM. Diabetes and Metabolic Syndrome: Clinical Research and Reviews, 11(2017), S783-S787. doi:10.1016/j.dsx.2017.05.017

Avogaro, A., \& Fadini, G. P. (2019). Microvascular complications in diabetes: A growing concern for cardiologists. International Journal of Cardiology, 291, 2935. doi:10.1016/j.ijcard.2019.02.030

Carretero Gómez, J., \& Arévalo Lorido, J. C. (2018). Clinical assessment and treatment of diabetes in patients with chronic kidney disease. Revista Clinica Espanola, 218(6), 305-315. doi:10.1016/j.rce.2018.03.016

Chao-Hung, C., Kun-Der, L., Ke, L.Y., \& Liang, C.J. (2019). O-GlcNAcylation disrupts STRA6-retinol signals in kidneys of diabetes. Biochimica et Biophysica Acta General Subjects, 1863(6), 1059-1069. doi:10.1016/j.bbagen.2019.03.014

Chen, Q., Wang, J., \& Huan, X. (2017). Comparative analysis of diabetic nephropathy and non-diabetic nephropathy disease. Saudi Journal of Biological Sciences, 24(8), 1815-1817. doi:10.1016/j.sjbs.2017.11.019

Chowdhury, A., Khan, H., Lasker, S. S., \& Chowdhury, T. A. (2019). Fasting outcomes in people with diabetes and chronic kidney disease in East London during Ramadan 2018: The East London diabetes in Ramadan survey. Diabetes Research and Clinical Practice, 152, 166-170. doi:10.1016/j.diabres.2019.05.022

Ghandour, R., Mikki, N., Abu Rmeileh, N. M. E., Jerdén, L., Norberg, M., Eriksson, J. W., \& Husseini, A. (2018). Complications of type 2 diabetes mellitus in Ramallah and Al-Bireh: The Palestinian Diabetes Complications and Control Study (PDCCS). Primary Care Diabetes, 12(6), 547-557. doi:10.1016/j.pcd.2018.07.002

Hsieh, Y. L., Lee, F. H., Chen, C. L., Chang, M. F., \& Han, P. H. (2016). Factors influencing intention to receive examination of diabetes complications. Asian Nursing Research, 10(4), 289-294. doi:10.1016/j.anr.2016.10.004

Hughes-Carter, D. L., Liu, C. C., \& Hoebeke, R. E. (2018). Improved screening and diagnosis of chronic kidney disease in the older adult with diabetes. Journal for Nurse Practitioners, 14(8), 626-632.e3. doi:10.1016/j.nurpra.2018.07.008

Julia, B., de Almeida-Pititto, B., \& Ferreira, S. R. G. (2019). Diabetic kidney disease in prediabetes. Obesity Medicine, 15, 100105. doi:10.1016/j.obmed.2019.100105 
Laddha, A. P., \& Kulkarni, Y. A. (2019). Tannins and vascular complications of diabetes: An update. Phytomedicine, 56, 229-245. doi:10.1016/j.phymed.2018.10.026

Lee, S. J., \& Chung, C. W. (2014). Health behaviors and risk factors associated with chronic kidney disease in Korean patients with diabetes: The fourth Korean national health and nutritional examination survey. Asian Nursing Research, 8(1), 8-14. doi:10.1016/j.anr.2013.11.001

Limkunakul, C., de Boer, I. H., Kestenbaum, B. R., Himmelfarb, J., Ikizler, T. A., \& Robinson-Cohen, C. (2019). The association of glycated hemoglobin with mortality and ESKD among persons with diabetes and chronic kidney disease. Journal of Diabetes and Its Complications, 33(4), 296-301. doi:10.1016/j.jdiacomp.2018.12.010

Lopes-Virella, M. F., Baker, N. L., Hunt, K. J., Hammad, S. M., Arthur, J., Virella, G., \& Klein, R. L. (2019). Glycosylated sphingolipids and progression to kidney dysfunction in type 1 diabetes. Journal of Clinical Lipidology, 13(3), 481-491. doi:10.1016/j.jacl.2019.03.005

Luthfa, I., \& Ardian, I. (2019). Effects of family empowerment on increasing family support in patients with type-2 diabetes mellitus. Nurse Media Journal of Nursing, 9(1), 58-68. doi:10.14710/nmjn.v9i1.22501

Nejhaddadgar, N., Darabi, F., Rohban, A., Solhi, M., \& Kheire, M. (2018). Effectiveness of self-management program for people with type 2 diabetes mellitus based on PRECEDE PROCEED model. Diabetes \& Metabolic Syndrome: Clinical Research \& Reviews, 13(1), 440-443. doi:10.1016/j.dsx.2018.08.016

Rivandi, J., \& Yonata, A. (2015). Hubungan diabetes melitus dengan kejadian gagal ginjal kronik [Relationship between diabetic nephropathy and chronic kidney disease's prevalences]. Medical Journal of Lampung University, 4(9), 27-34.

Sari, N., \& Hisyam, B. (2014). Hubungan antara diabetes mellitus tipe II dengan kejadian gagal ginjal kronik di rumah sakit PKU Muhammadiyah Yogyakarta periode Januari 2011- Oktober 2012 [Relationship between type II diabetes mellitus and chronic kidney failure at PKU Muhammadiyah hospital on January 2011-October 2012]. Jurnal Kedokteran dan Kesehatan Indonesia, 6(1), 11-18.

Sari, Y., Purnawan, I., Taufik, A., \& Sumeru, A. (2018). Quality of life and associated factors in Indonesian diabetic patients with foot ulcers. Nurse Media Journal of Nursing, 8(1), 13-24. doi:10.14710/nmjn.v8i1.16815

United States Renal Data System. (2018). USRDS annual data report. Retrieved from https://www.usrds.org/adr.aspx

World Health Organization (WHO). (2016). Global report on diabetes. Retrieved from https://www.who.int/diabetes/global-report/en/ 